\title{
Dimensões da democratização da ciência-tecnologia no âmbito da educação CTS
}

\author{
Dimensions of democratization of science-technology in the \\ context of STS education
}

\author{
Suiane Ewerling da Rosa (suiane.rosa@ufob.edu.br) \\ Universidade Federal do Oeste da Bahia \\ Roseline Beatriz Strieder (roseline@unb.br) \\ Universidade de Brasília
}

\begin{abstract}
Resumo:
Considerando que o movimento Ciência-Tecnologia-Sociedade (CTS) tem como um dos seus propósitos centrais a busca por processos ampliados de participação em temas sociais de ciência-tecnologia (CT), neste artigo, propomos discussões que visam ampliar entendimentos sobre processos democráticos em CT. Para isso, consideramos três perspectivas distintas de democratização que envolvem as dimensões: i) linear e hierarquizada; ii) dialógica; e, iii) produção conjunta e compartilhada de conhecimentos. Como encaminhamentos, associamos essas dimensões a sentidos e perspectivas relativos à educação CTS. Além disso, ressaltamos a importância de problematizar aspectos sobre processos democráticos na educação CTS, visto que esses, muitas vezes, estão fundamentados por discursos vazios de significados. Portanto, defendemos que em uma educação que tenha como propósito a constituição de uma cultura de participação, como é o caso de CTS, discussões como essas são essenciais, necessárias e não podem ser passíveis de pouca criticidade.
\end{abstract}

Palavras-chave: Ciência-Tecnologia-Sociedade; Freire; PLACTS; Democratização.

\begin{abstract}
:
Considering that the Science-Technology-Society (STS) movement has as one of its central purposes the search for expanded processes of participation in social sciencetechnology (ST) topics, in this article, we propose discussions aimed at broadening understanding of democratic processes in ST. For this, we consider three distinct perspectives of democratization that involve the dimensions: i) linear and hierarchical; ii) dialogic; and iii) joint and shared production of knowledge. As referrals, we associate these dimensions with meanings and perspectives related to STS education. In addition, we emphasize the importance of problematizing aspects about democratic processes in STS education, since these are often based on voiceless discourses of meanings. Therefore, we argue that in an education whose purpose is the constitution of a culture of participation, as in the case of STS, discussions such as these are essential, necessary and can not be subject to little criticism.
\end{abstract}

Key-words: Science-Technology-Society; Freire; PLACTS; Democratization. 


\section{CTS: SURGIMENTO, PROPÓSITOS E REPERCUSSÃO EDUCACIONAL}

Discussões sobre as relações CTS tiveram início em meados do século $\mathrm{XX}$, como resposta às transformações sociais acarretadas pelo desenvolvimento científicotecnológico e aos problemas políticos, econômicos e ambientais a ele relacionados (GARCÍA; CEREZO; LUJÁN, 1996). Segundo esses autores, em países da América do Norte e Europa, dentre as reinvindicações deste movimento, estava a busca por uma maior participação da sociedade nos rumos do desenvolvimento científico-tecnológico. No que se refere à América Latina, os estudos sobre CTS têm sido agregados no denominado Pensamento Latino-americano em CTS (PLACTS), contestavam o modelo de desenvolvimento adotado nos países Latino-Americanos, linear e contrário às necessidades regionais, e reivindicavam um projeto de política científica e tecnológica claro e coerente com a realidade desses países (DAGNINO; THOMAS; DAVYT, 2003).

Num primeiro momento, as discussões sobre CTS desenvolveram-se nas universidades e no âmbito de movimentos sociais; posteriormente, repercutiram para o contexto educacional. Especificamente no Brasil, década de 1990 é compreendida como um marco, pois foi quando tiveram início as primeiras pesquisas de mestrado e/ou doutorado envolvendo a temática CTS na educação científica (SANTOS, 2008). Também nessa década foi promulgada a Lei de Diretrizes e Bases da Educação, vigente nos dias atuais, e, a partir dela, uma série de documentos oficiais que têm orientado a educação brasileira. A partir da análise desses documentos, vários pesquisadores têm afirmado que desde o final do século passado, há, no Brasil, uma proposição curricular que aponta para a abordagem das inter-relações CTS, ainda que repleta de lacunas e ambiguidades (ver, por exemplo: STRIEDER et al., 2016).

Embora um movimento partilhado em diferentes contextos e países, desde sua origem, tem sido enfatizada a polissemia da Educação CTS e a necessidade de compreendê-la para melhor definir potencialidades e limitações dessa perspectiva, referenciais e estratégias de ação (AIKENHEAD, 2003). No Brasil, segundo Strieder e Kawamura (2017), a educação CTS tem assumido diferentes propósitos educacionais (desenvolvimento de percepções, questionamentos e compromissos sociais) e abarcado discussões em torno da racionalidade científica, do desenvolvimento tecnológico e da 
participação social. Neste trabalho em particular, destacamos a participação social, que, segundo as autoras, é discutida considerando um amplo espectro de possibilidades que vai desde a informação sobre temas socioambientais até a reivindicação pela democratização das decisões relacionadas à CT.

Assim, em linhas gerais, apesar da diversidade de abordagens, pode-se afirmar que há, no âmbito da educação CTS, uma preocupação com a democratização das decisões envolvendo CT. Mas, o que queremos dizer com "democratizar as decisões relacionadas à CT’? E, além disso, como contemplar essa preocupação em práticas educativas no contexto do ensino de ciências? A busca por respostas a essas questões é o objetivo deste artigo que apresenta, portanto, reflexões em torno dos sentidos e perspectivas atribuídos à democratização de decisões no âmbito da educação científica CTS.

De maneira geral, percebe-se a democratização como um objetivo central da educação CTS, considerado teoricamente nas práticas educativas, mas não refletido criticamente (ROSA, 2014). Em virtude disso, e entendendo que processos democráticos e de participação em tomadas de decisão constituem-se uma construção histórico-cultural, neste artigo, problematizaremos criticamente de que maneira essas perspectivas são vistas e construídas no contexto educacional, apontando limitações e potencialidades tendo como horizonte a busca por uma constituição cultural de uma sociedade mais democrática em CT.

\section{DIMENSÕES DA DEMOCRATIZAÇÃO DA CT E SUA ARTICULAÇÃO COM PERSPECTIVAS EDUCACIONAIS}

A democratização de decisões pode ser considerada um campo de estudos complexo e polissêmico, assumindo significados distintos para diferentes sujeitos e contextos. Particularmente no âmbito da educação científica, Silva e Lima Júnior (2017) em uma revisão de literatura em periódicos nacionais da área de educação/ensino de ciências, apresentaram dois sentidos atribuídos à democracia, associados a: i) democracia escolar participativa; e, ii) democracia ambiental participativa. Esses foram caracterizados devido a evidência apresentada nos artigos sobre diferentes níveis de participação. Segundo esses autores, os modelos surgem de uma expansão dos estudos sobre democracia participativa, em especial no aprofundamento sobre cidadania em 
pesquisas da educação em ciências. O primeiro modelo caracteriza-se pela participação em sala de aula ou gestão escolar que possibilita espaços igualitários nos processos de decisão. Já o segundo está relacionado com espaços vivenciados pela sociedade, no qual as definições políticas interagem e influenciam nas relações sociais com o meio ambiente no processo de construção da cidadania.

No caso da educação CTS, entendemos que ambos os modelos propostos por Silva e Lima Júnior (2017) comparecem em práticas educativas, na educação básica e formação de professores, como também indica o trabalho de Rosa e Araújo (2017). Nesse, verificou-se que os discursos dos autores, relacionados à participação e pautados pelo desenvolvimento das práticas realizadas, estavam alinhados à perspectiva de "dar voz aos sujeitos", como superação da "cultura do silêncio" (FREIRE, 2005) para uma prática dialógica. A categoria da participação, como eixo central dos processos democráticos, esteve marcada principalmente pelo aumento do engajamento dos estudantes em sala de aula, com voz ativa e ouvida no contexto educacional, mas também, mesmo que em minoria, por processos mais ampliados de participação, como um despertar para a problematização e modificação de situações vivenciadas. Destacase que essas perspectivas se aproximam dos propósitos educacionais e sociais freireanos, que defendem que os sujeitos devem sair da condição silenciada e passiva para uma postura de consciência crítica, dialógica e de transformação social. Estes objetivos, quando visados para problemas sociais relacionados à CT, constituem-se pressupostos centrais na busca por processos democráticos pautados pela articulação Freire-CTS.

Esses trabalhos (realizados por Silva e Lima Júnior e Rosa e Araújo) contribuem para entendermos posturas assumidas pelos sujeitos em práticas educativas participativas, porém, não aprofundam discussões relacionadas ao papel dos conhecimentos nesses processos. Nessa linha, destacamos o trabalho realizado por Samagaia (2016), ainda que voltado à divulgação científica. Esse estudo, fundamentado principalmente nas teorias de Michel Callon, enfatiza as relações existentes entre ciência e sociedade e discute três modelos distintos de comunicação científica: modelo de instrução pública, modelo do diálogo e, modelo da coprodução dos saberes. Como será discutido adiante, esses modelos, articulados às reflexões de Paulo Freire, Edgard Morin e do PLACTS, contribuíram para a delimitação de diferentes dimensões 
relacionadas à democratização das decisões em $\mathrm{CT}$, vistas e construídas no contexto educacional.

Assim, tomando por base esses estudos, neste trabalho, aprofundaremos as discussões sobre democratização da CT no âmbito da educação científica, em concreto, elaboramos três perspectivas distintas de democratização, as quais serão discutidas a seguir e envolvem as seguintes dimensões: linear e hierarquizada, dialógica e da produção conjunta e compartilhada de conhecimentos. A nosso ver, essas três perspectivas têm orientado as práticas educativas CTS, ainda que de forma não explícita ou inconsciente. Uma clareza com relação a elas pode contribuir, portanto, para reflexões em torno das práticas, em especial, no que diz respeito às suas potencialidades e limitações para a formação de sujeitos aptos a participar de processos decisórios envolvendo questões relacionadas à CT.

\section{DIMENSÃO LINEAR E HIERARQUIZADA}

Para aprofundar e problematizar essa primeira dimensão, partimos do modelo de democratização da CT denominado por Callon (1998) de instrução pública. Este caracteriza-se principalmente por envolver dois grandes grupos sociais, que podem ou não se relacionar nas situações existentes. $O$ primeiro grupo refere-se aos cientistas, que são tidos como os únicos atores capazes de contribuir no processo de produção da ciência; são os mais aptos e, muitas vezes, os únicos a avaliarem da maneira mais correta as situações complexas que envolvem situações científicas. O público, que envolve os demais atores sociais, é considerado o segundo grupo e só se distingue do primeiro grupo pela formação ou grau de conhecimento sobre ciência. Portanto, "são considerados como uma massa homogênea de pessoas que dependem do cientista para compreender de forma apropriada as questões relacionadas à ciência" (SAMAGAIA, 2016, p. 37). A função do público, neste modelo, está em observar, aguardar e acompanhar o desenvolvimento e conclusões obtidas pelos cientistas, recebendo os produtos e os usando de maneira benéfica em sua vida cotidiana. O cientista, por outro lado, tem a função de informar e/ou formar os outros atores, visando ações que envolvem a constituição de novos especialistas/cientistas e contribuições para que o 
público em geral compreenda as avaliações ou os conteúdos da ciência (CALLON, 1998).

Nessa perspectiva os riscos atrelados ao desenvolvimento da CT são ignorados e não há discussões sobre possíveis precauções. Para Callon (1998) os riscos são basicamente de dois tipos: objetivos e subjetivos. Os riscos objetivos são vistos como reais e que podem ser analisados pelos cientistas. Neste modelo, os riscos devem ser identificados, controlados e assumidos. Não há margem para dúvidas e questionamentos. Já a compreensão dos riscos subjetivos é àquela considerada irracional e descritiva, ou seja, que não se compromete ou faz referência ao conhecimento atestado e objetivado. Um exemplo referente ao risco subjetivo, citado por Samagaia (2016), é o do consumo dos transgênicos, isso porque os questionamentos ao risco se dariam por inferências ou pesquisas que parte da comunidade científica não valida. Assim, constituem-se de indagações e receios que são, muitas vezes, levantadas por atores sociais que não possuem o conhecimento necessário, logo são de "pouca relevância, subjetivos e secundários" (p. 53). Alan Irwin, outro autor mencionado por Samagaia (2016), exemplifica o parâmetro do risco a partir do caso que no Brasil ficou conhecido como "vaca louca". Para a sua análise, Irwin avalia os discursos produzidos pelas autoridades governamentais, industriais e científicas que foram levados à esfera social pela mídia no momento inicial do caso na Inglaterra e Reino Unido. Devido a esse contexto pouco se sabia sobre a doença e possíveis transmissões para os seres humanos, no entanto os discursos das autoridades, que estavam alinhados ao viés científico e industrial, explicitavam a não existência de riscos objetivos e científicos associados à carne produzida e comercializada e, portanto, não havia qualquer dúvida quanto ao seu consumo. Perspectiva que posteriormente se mostrou errônea. Nesses discursos, a ciência é vista como elemento chave e essencial para olhar o problema, e o público é o ator social que precisa ser protegido e que não é, nem precisa ser consultado.

A controvérsia científica também é um parâmetro a ser destacado nessa relação entre ciência e sociedade. Neste modelo, a científica é vista como a única controvérsia que pode existir e, mesmo assim, não deve ser transmitida ao público. Ela está associada ao processo de construção da ciência e, portanto, surge quando esse processo está incompleto e, consequentemente, não é consensual. Já as controvérsias sociocientíficas 
que alcançam a esfera pública são vistas como falta de conhecimento e/ou compreensão desses atores sobre a explicação dada pelo cientista (SAMAGAIA, 2016).

Essa dimensão possui elementos marcantes do paradigma da simplificação, ou seja, de um pensamento linear, fragmentado e hierarquizado da CT. Morin (2015) em seus estudos considera que a organização/construção do conhecimento, e, portanto, da ciência, se dá pela seleção dos dados que depende da sua significância ou não. Para essa operação, faz-se necessário uma organização do pensamento, ou seja, princípios ocultos que orientam/conduzem nossa visão do mundo, muitas vezes sem que tenhamos consciência disso. Neste sentido, para o autor, uma das formas de pensamento é o que ele denominada de simplificação. Nesta, a ciência tem sido considerada, cada vez mais, como algo distante e incompreensível socialmente. Essa situação, que inibe qualquer processo de participação dos cidadãos em CT, está associada com a própria lógica de construção da ciência, isso porque "vivemos sob o império dos princípios de disjunção, de redução e de abstração" (p. 11). O pensamento simplificado procura organizar o conhecimento utilizando princípios que separa, une, hierarquiza e centraliza os pensamentos, ou seja, "separa o que está ligado (disjunção), ou unifica o que é diverso (redução)" (p. 59). Apesar dessa lógica de construção da ciência ter contribuído para grandes progressos do conhecimento científico, ela trouxe além de consequências nocivas, marcantes a partir do século XX, um distanciamento, ainda maior, da ciência e sociedade.

Enquanto exercício articulador e de síntese para entendimentos sobre a democratização da CT, destacamos que essa dimensão é balizada por uma comunicação/interação linear e hierarquizada de cima para baixo. O conhecimento válido é apenas o científico, produzido por especialistas, e os aspectos valorativos são aqueles ditos objetivos, intrínsecos à ciência.

Articulado às discussões presentes na literatura sobre CTS podemos relacionar essas discussões às da suposta neutralidade da CT, em especial, ao mito da neutralidade/superioridade do modelo de decisões tecnocráticas, fundamentado na crença de eliminar/neutralizar a sociedade na tomada de decisão sobre temas científicotecnológicos (AULER, 2002). Nesta compreensão, o papel dos atores sociais é bem definido e hierarquizado, aos cientistas/pesquisadores cabe o papel de todos os direcionamentos da CT, de maneira ideologicamente neutra e isenta de influências 
sociais. Aos demais atores o compromisso está, por exemplo, no bom uso dos produtos da CT. A interação existente entre os atores sociais é orientada em uma direção única, que vai da ciência, dos cientistas, para a sociedade em geral. Tanto o modelo de instrução pública quanto concepções que alimentam a supostamente neutralidade da CT -mito tecnocrático- favorecem a intervenção apenas dos especialistas, decidindo o que seria correto e necessário para a sociedade, inviabilizando qualquer participação da sociedade nas discussões/direcionamentos/decisões envolvendo a CT (GARCIA; CEREZO; LÓPEZ, 1996). A participação, neste contexto, estaria no recebimento/aceitação passiva da $\mathrm{CT}$.

A construção de conhecimento, a ciência, nestas discussões é vista como universal, objetiva e de verdades inquestionáveis. Esta imagem contribui para alimentar concepções ingênuas, como a que entende que os cientistas são os únicos atores capazes de direcionar a CT por possuírem o melhor dos saberes, potencializando as decisões tecnocráticas. Nessa concepção, a ciência é uma instituição separada do restante da sociedade e é regida por regras próprias que projetam sempre o seu progresso, ou seja, os aspectos valorativos envolvidos nessa construção são intrínsecos a própria ciência. A sociedade em geral, neste processo supostamente democrático, são receptoras de informação, formação e usam os produtos científico-tecnológicos. Além disso, associado à visão instrumental problematizada por Dagnino (2010), os impactos produzidos pela $\mathrm{CT}$, caso existem, estão associados ao mau uso dado e não à ciência em si, pois cabe à sociedade usar a ética para dar a este bom uso. Visto que "a ética entra como uma solução de um problema que não diz respeito aos cientistas" (p. 309).

Além disso, podemos relacionar as discussões realizadas nessa categoria, de maneira geral, com aquelas práticas educacionais próximas ao contexto da educação bancária (FREIRE, 2005). Nesta, o professor, especialista da área, transmite o conhecimento para o restante dos atores sociais que se encontram naquele contexto, no caso os estudantes. Esses são vistos como sujeitos passivos, vazios de conhecimento e nada tem a dizer sobre o tema trabalhado, mas que ao passar pelo processo educacional deveriam estar habilitados para descrever e justificar o mundo à sua volta. O papel dos estudantes está na aceitação daquilo que é transmitido pelo especialista e caso eles não consigam reproduzir os conhecimentos científicos solicitados, o problema encontra-se na falta de compreensão e informação do estudante e não da dinâmica do processo, do 
tema trabalhado, proposição curricular, pressupostos e objetivos e, muito menos, do especialista.

Referente à educação CTS, por mais que os objetivos dessa proposição estejam alinhados a pressupostos de fato democráticos frente a temas sociais de CT, podemos destacar práticas e propostas educacionais que podem contribuir para a dimensão linear e hierarquizada de democracia. Essas são, por exemplo, organizadas por problemas que mencionam e são solucionados apenas pelo conhecimento científico-tecnológico e, que são direcionadas por uma dinâmica que vai, de forma majoritariamente linear, do professor ao estudante, e não de proposições dialógicas que visam a construção problemática e ativa frente a situação. Além disso, podemos destacar também proposições educativas no qual a elaboração e organização são desenvolvidas unicamente por especialistas (agentes externos a unidade escolar ou professores unicamente), não envolvendo a interação ampla dos atores sociais, como professores, estudantes e ainda comunidade escolar ou local, que poderão contribuir na definição e interação de possíveis demandas ou temas a serem trabalhados. Destaca-se que essa perspectiva é quase que hegemônica nas nossas escolas e que modificá-la constitui-se além de um grande desafio educacional, um conjunto de posições contraditórias, visto que para alguns, esse papel é de fato do professor ou ainda de proposições curriculares externas.

Diante do proposto destacamos que a dimensão discutida de democratização da CT minimiza os olhares para os problemas sociais, visto que são pautados e construídos apenas sobre conhecimentos e valores de CT. Apesar do problema, na educação CTS, ser voltado para temas sociais do cotidiano do estudante, se o seu desenvolvimento não considerar a insuficiência do conhecimento técnico-científico, de aspectos axiológicos da CT e da interação entre diferentes atores sociais, possivelmente essas práticas estarão contribuindo para uma "democratização" da CT linear e hierarquizada, fragilizando a construção de uma sociedade mais ativa, engajada e participativa frente a processos decisórios.

Assim, mesmo que as discussões apresentadas sejam consideradas como hegemônicas e legitimadas em muitos espaços institucionais, inclusive educacionais, reverberando e alimentando concepções das suposta neutralidade da CT, Samagaia (2016) destaca que o modelo da instrução pública, pelo menos na Europa, começou a 
apresentar declínios na década de setenta, devido a fatos emblemáticos ocorrido e que abalaram "a confiança confirmada nas instituições produtoras de ciência e em seus representantes, exigindo dos cidadãos a entrada no processo de transformação para a confiança decidida" (p. 57). Segundo a autora, apoiada em Boy (2007), esse período de transição esteve articulado a busca de novas estratégias comunicacionais visando uma reconstrução de confiança. Como resposta a essas demandas surgem novas práticas alicerçadas pelo viés dialógico e de mais interação entre os atores sociais. E é neste sentido que Callon (1998) apresenta os próximos modelos de participação entre diferentes atores sociais.

\section{DIMENSÃO DIALÓGICA}

A segunda dimensão que nos ajuda a compreender o processo de democratização da CT, e que começa a romper com a lógica do pensamento da simplificação, tem como pano de fundo uma proposição dialógica entre atores e saberes. Para aprofundarmos essa discussão nos apoiaremos no modelo de debate público de Callon (1998), traduzido por Samagaia (2016) como modelo do diálogo. Neste, a ciência é vista como um conhecimento essencial para a sociedade, porém insuficiente na identificação e solução dos problemas reais vivenciados. O destaque voltado para este modelo está no fato de que o conhecimento científico só será utilizado de maneira adequada para a solução de problemas sociais caso haja, de maneira racional e consciente, a integração e ampliação de variáveis envolvidas e não apenas àquelas pré-definidas cientificamente. A interação/comunicação promovida vai além da instrução pública de formação e comunicação linear, para o diálogo entre os diferentes atores sociais envolvidos, como especialistas e não especialistas. Este diálogo, segundo Samagaia (2016), deve ter como fundamento a compreensão e inclusão gradativa do conhecimento do outro na sua leitura de mundo, bem como na busca por alternativas para as demandas sociais vivenciadas, seja no âmbito individual ou de um coletivo. Nesta perspectiva, os conhecimentos diversos são considerados, no entanto assim como no modelo da instrução pública os cientistas ainda são os únicos atores sociais aptos e capazes a produzirem conhecimento científico (CALLON, 1998). O que diferencia este modelo é o fato que a contribuição do especialista e seu conhecimento são vistos como limitantes, 
pois ao referir-se a temas de outras naturezas há envolvimento de variáveis que ultrapassam a área científica.

A ciência é vista como um conhecimento marcado por incertezas, riscos e benefícios que são avaliados e assumidos por todos os atores sociais envolvidos. Os riscos, diferentemente do modelo anterior, são parte constituinte da produção e do produto científico e, diante disso, não podem ser totalmente controlados. É oriundo deste contexto que há a necessidade de espaços para o diálogo, visto que o mesmo está no enriquecimento e compartilhamento entre os atores sociais, pois esses já não são mais vistos como uma "massa homogênea" e sim são seres únicos, com saberes específicos/locais e, portanto, "fonte de informação que não pode ser desconsiderada pelo cientista" (SAMAGAIA, 2016, p. 59).

As controvérsias existentes são vistas como desacordos, e não como falta de conhecimento, e, por isso, na resolução de problemas sociais, o conhecimento científico não deve ser utilizado exclusivamente e de forma isolada, já que ele é visto como insuficiente. O transgênico, citado por Samagaia (2016), envolve tanto a área científica quanto aspectos valorativos e outros conhecimentos, como ética, economia, política, ambiental e, também, direcionamentos de escolhas e organização de vida. O cientista, neste caso, poderia ser influenciado por interesses profissionais ou econômicos (CALLON, 1998). Assim, as controvérsias sociocientíficas são reconhecidas e ganham espaço considerável. Para evitar que se transformem em crise, é enfatizado que "o exercício do diálogo, a existência de espaços que provoquem e favoreçam estas trocas são essenciais" (SAMAGAIA, 2016, p. 60).

Devido à complexidade de lidar com situações sociais, Callon (1998) destaca o potencial de espaços de discussão e deliberação que visam criar condições que ajudam enriquecer elas, principalmente devido as suas problemáticas e controvérsias. Espaços esses denominado de "fóruns híbridos", fóruns porque corresponde a espaços abertos que envolvem um coletivo e híbrido porque os atores sociais são heterogêneos, incluindo especialistas, políticos, técnicos e leigos (CALLON; LASCOUMES; BARTHE, 2009). Os fóruns são vistos como essencial na proposição dialógica e a participação de cada ator social é essencial, visto que possuem papeis centrais e únicos nos processos decisórios, já que cada um contribui com o que conhece e vivencia, possibilitando a produção e compartilhamento de saberes mais ampliados para os 
problemas sociais vivenciados. O exemplo destacado por Samagaia (2016), apoiada em Alan Irwin, retrata novamente o caso da doença da vaca louca, que ocorreu no final da década de oitenta na Europa (IRWIN, 2008), situação no qual o modelo do diálogo poderia ter sido usado. Samagaia (2016) relata que na época o controle foi constituído e realizado impostamente, sem diálogo com os trabalhadores dos abatedouros, atores estes que poderiam contribuir na identificação de sintomas e problemas e também responsáveis por colocar o tratamento em prática. Porém, todo o processo foi desenvolvido unicamente pelos cientistas. Aos demais atores restou a execução, bem feita, das decisões tomadas pelos cientistas. E ainda, Irwin destaca que a maneira como a operação aconteceu subentende uma situação não real entre um abatedouro e um laboratório, visto que neste há condições de operação que permitem um controle sobre as diversas variáveis envolvidas. Ou seja, "o resultado é uma situação caótica e descontrolada que acolhe transgressão de uns e conivência de outros" (p. 74).

Os aspectos destacados neste modelo se aproximam de pressupostos teóricos da educação CTS, como, por exemplo, a inserção de diversos elementos valorativos, a interação entre diferentes atores sociais e, de alguma maneira, a inclusão de conhecimentos outros, além do técnico-científico, para elucidar os temas sociais de CT investigados e analisados. Destaca-se que esses aspectos ainda não são majoritários nessa linha de investigação e são, muitas vezes, apontados de maneira apenas teórica, conforme analisado em Rosa (2014). A defesa pela inclusão e consideração de conhecimentos outros, que não apenas o científico nos problemas sociais vivenciados é marcante também nos trabalhos de Sousa Santos (2007). Ele defende que ao considerar como válido apenas o conhecimento científico, muitas realidades da sociedade são deixadas de fora, já que "há práticas sociais que estão baseadas em conhecimentos populares, conhecimentos indígenas, conhecimentos camponeses, conhecimentos urbanos, mas que não são avaliados como importantes ou rigorosos" (SOUSA SANTOS, 2007, p. 29). Logo, esses conhecimentos não são críveis justamente por não possuírem o rigor científico, e, portanto, são, muitas vezes, produzidos como não existentes ou simplesmente silenciados. E não apenas esses conhecimentos são desconsiderados como também os atores sociais que os produzem. A defesa do autor, e que corrobora com a proposição do modelo dialógico, está em propor "uma ecologia mais ampla de saberes, em que o saber científico possa dialogar com o saber laico, com 
o saber popular, com o saber dos indígenas, com o saber das populações urbanas, com o saber camponês" (p. 32-33). Essa perspectiva, assim como no modelo de Callon (1998), entende que todas as práticas entre os seres humanos, e destes com a natureza, implicam em mais de uma forma de saber, ou seja, os atores sociais são únicos, por isso possuem saberes específicos dos locais aos quais pertencem e vivenciam.

Voltado para o contexto educacional CTS destacamos o potencial das práticas educativas fundamentadas nos pressupostos freireanos. Essas têm como alicerce uma educação dialógica, problematizadora e de leitura de mundo, perspectiva entendida de ser alcançada caso haja a superação da "cultura do silêncio" para a constituição de uma sociedade mais democrática. A articulação Freire-CTS, segundo Auler (2002), está no entendimento que alfabetizar, para Freire (2005), é muito mais do que ler palavras, deve propiciar a leitura do mundo. Os sujeitos através da leitura do mundo e da palavra terão condições de transformar a sua consciência ingênua em crítica, transformando socialmente suas realidades. Para a leitura crítica da realidade, dos problemas socioambientais vivenciados, que está condicionada, cada vez mais pelo avanço do campo científico-tecnológico, torna-se fundamental compreender as relações existentes nessas interações. Logo, se o problema é do campo social da CT, o mesmo deveria ser inevitavelmente articulado com: conhecimentos da realidade vivenciada, e não apenas do campo da CT; valores que interagem com essas dimensões, como econômico, político, ética, moral, entre outros; e ainda, diálogo entre os atores sociais envolvidos nessas interações, visto que se almeja transformações sociais.

Enquanto potencialidades educacionais, as práticas educativas que tem como horizonte a articulação Freire-CTS, além de promoverem diálogo entre campos distintos de conhecimento e valores sobre um problema social (que algumas práticas CTS não articulada ao viés freireano também possuem) tem como pano de fundo temas próximos da realidade vivida pelo estudante, às vezes oriundos de processos investigativos que resultam em temas geradores (FREIRE, 2005), de demandas e interesses sociais vivenciados. Ou seja, são temas nos quais os estudantes conseguem falar, que tem conhecimentos sobre, mesmo que não seja da área de CT. O conteúdo do diálogo, sob viés Freire-CTS, é pautado pelas leituras de mundo, suas vivências e como horizonte processos de transformação e entendimentos técnico-científicos sobre a realidade vivida, mas esta sem desconsiderar outras dimensões. O diálogo promovido entre os 
atores sociais, em especial professores e estudantes, encontra-se em um processo ativo, de interação. No entanto, percebe-se que muitas dessas práticas pautam-se de um diálogo orientado para levantamento, problematizações e dúvidas sobre os temas trabalhados e não um engajamento integral no processo educacional, de construção do conhecimento, perspectiva que se aproxima ao modelo do Callon (1998). Ou seja, há diálogo entre os sujeitos, "vozes ativas" no processo, porém os professores/especialistas/gestores, muitas vezes, ainda são os únicos atores capazes de produzirem conhecimento.

\section{DIMENSÃO DE PRODUÇÃO CONJUNTA E COMPARTILHADA}

A última dimensão que contribui para refletirmos sobre a democratização da CT rompe com a forma de pensamento e produção de ciência/conhecimento simplificador. Freire (2005) aponta que uma das características da existência humana é a sua condição de inacabamento e a capacidade de reconhecer e transformar essa condição. Neste sentido, compreender o processo da complexidade humana e social é de extrema importância. Complexidade entendida como uma nova forma, desafio e motivação para pensar e agir no mundo. Diante disso, e para o enfrentamento do pensamento da simplificação, Morin (2015) discute o pensamento complexo, este entendido não por estar completo, mas sim da própria incompletude do conhecimento. $\mathrm{Ou}$ seja, considerando que somos seres sociais, físicos, biológicos, culturais, psíquicos, ao mesmo tempo e em transformação, "a complexidade é aquilo que tenta conceber a articulação, a identidade e a diferença de todos esses aspectos” (MORIN, 2014, p. 176). O pensamento simplificado, de outra maneira, separa eles ou unifica-os por uma redução, denominada pelo autor de mutilante. Reconhecendo que o pensamento da complexidade tem dentre outros aspectos, a compreensão de que o todo necessita das partes, e as partes necessitam do todo, a terceira dimensão da democratização da CT possui fundamentos que, no nosso entender, são melhores compreendidos, compartilhados e efetivados diante de um pensamento complexo.

Assim, essa dimensão da democratização da CT se fundamenta no terceiro modelo de Callon (1998), denominado de coprodução de conhecimentos, e é descrito por Samagaia (2016) como recente na literatura, relativamente incipiente e menos convergentes nas análises dos autores que o estudam. Este modelo, assim como os 
outros, também coloca o conhecimento científico como essencial no processo. Porém, diferencia-se em um aspecto central, a possibilidade de produção conjunta de conhecimento por grupos heterogêneos.

O cientista, na dinâmica de desenvolvimento, tem o papel de referenciar o problema sobre o viés do conhecimento científico e em momento posterior apontar as conclusões obtidas localmente para que possam ser aceitas na comunidade científica. Os demais atores sociais têm a função de especialista das condições locais e das demandas vivenciadas diretamente, demandas que possuem papel fundamental, pois são elas que mobilizarão a construção do conhecimento e o trabalho coletivo tendo como objetivo ampliar os entendimentos sobre o tema. A organização do processo se dá pela ação constante do cientista que se articula com os conhecimentos, trocas e aspectos trazidos pelos demais atores sociais, visto que "o produto deste processo será tão rico e pertinente quanto forem estreitas e constantes as relações dentro do grupo", sendo que a ciência deva ser "enquadrada e alimentada em um sistema que inclua a participação da sociedade" (SAMAGAIA, 2016, p. 78).

A ciência é parte essencial de um problema complexo articulado a esfera social, portanto o conhecimento científico é visto como não isento de influências sociais logo, não neutro. Os atores sociais que possuem papeis centrais neste modelo têm conhecimentos que são oriundos do seu entendimento sobre o mundo, influenciado por diversas questões como idade, gênero, cultura, formação e, também, de alguma maneira, dos fenômenos naturais associados a eles. Esses atores podem, diante de certas condições, ter saberes que serão desenvolvidos na compreensão científica, podendo ser uma contribuição para a própria ciência. Callon (1998) destaca que os atores sociais, em geral, envolvidos nesse processo, são doentes e seus familiares ou ainda uma comunidade que vive em uma região de contaminação ou que irá sofrer algum tipo de transformação que implica no modo de viver. Outro destaque apontado está no fato de que o local e os saberes individualizados dão conta da complexidade das situações singulares, mas sozinhos são insuficientes para a transformação da realidade vivida, aspecto que evidencia que o conhecimento leigo não deve substituir o conhecimento científico e sim ser articulado ao próprio processo de construção. O conhecimento que vai do mais universal (científico) ao mais específico (vivenciados pelos doentes, por exemplo) são discutidos, construídos e apropriados por um coletivo híbrido, que 
incluem especialistas e atores sociais "atingidos" e/ou interessados. Há uma aprendizagem coletiva sobre os diferentes conhecimentos. Estes se cruzam e geram o próprio processo de coprodução (CALLON, 1998).

Samagaia (2016) fundamentada em Callon, Lascoumes e Barthes (2009) caracteriza três critérios do processo de co-construção do conhecimento: 1) existência de um problema vivido por um grupo da sociedade; 2) a reunião destes atores sociais em um grupo que tem uma identidade fortemente compartilhada; e 3) ação participativa e colaborativa do grupo na busca por soluções das demandas que compartilham. O destaque deste modelo encontra-se no fato de que alguns leigos se tornam mais capazes de contribuir na construção do conhecimento na medida em que os mesmos são tocados por uma temática que pode ser transformada através deste conhecimento. O término do processo se dá pelo compartilhamento do conhecimento produzido entre todos os participantes, fazendo com que todos possam ser, mesmo que nem todos sejam, especialistas do problema investigado. Além disso, algumas soluções oriundas do processo poderão ser usadas em outros contextos, cabendo assim aos cientistas a função de continuação do processo investigativo para que o conhecimento seja incorporado à ciência (CALLON, 2009 apud SAMAGAIA, 2016).

O risco neste modelo é visto com algo intrínseco à ciência, e, portanto, ela é incapaz de produzir verdades inquestionáveis. Assim, as soluções científicas desenvolvidas para as demandas sociais têm seu campo de atuação restritas às variáveis consideradas, visto que fora delas a sua aplicação fica comprometida e envolve novos riscos que precisam ser melhor compreendidos. Processo que segundo Samagaia (2016) precisa ser organizado, de reflexão e de tomadas de decisão individual e coletivo.

Enquanto síntese destacamos a visão de Callon, Lascoumes e Barthes (2009 apud SAMAGAIA, 2016) que destacam que a potencialidade deste modelo está no engajamento para uma construção coletiva sobre um conhecimento de natureza científica que, ao ser concluída, deve ser passível de obtenção de legitimidade na ciência. A ciência não deve ser vista como algo que será substituída por conhecimentos outros. Pelo contrário, seu processo de reformulação é fundamentado na ideia de que a produção de conhecimento científico é voltada para atender demandas efetivamente de grupos sociais, e, por isso necessitam de produção conjunta. Junto a isso, espera-se "capacitar um amplo grupo de atores para que estes tenham autonomia de ação sobre o 
conhecimento produzido. Refletindo, discutindo, reformulando e questionando o conhecimento ou a aplicação deste sempre que necessário" (p. 88).

Como exemplo deste modelo Samagaia (2016), apoiada em Callon, Lascoumes e Barthes (2001), aponta o caso das miopatias, doenças neurológicas raras com pouco conhecimento no século passado e que devido a pouca incidência de casos não recebiam a atenção necessária do governo francês, local do relato, e nem da indústria farmacêutica. Esse contexto faz surgir um envolvimento de um grupo de pais que viviam com a doença dos seus filhos objetivando a transformação dos mesmos. Com essa demanda inicial e agrupamento de informações sobre a doença, o processo avança com o envolvimento de profissionais da área da saúde e pesquisadores interessados na investigação do problema. Após essas etapas, a associação dos pais comunica a esfera pública sobre a doença e como os demais poderiam contribuir e também do que o grupo híbrido pretendia fazer. Essa comunicação midiática, segundo a autora, possuía um duplo objetivo: solicitação e envolvimento social na busca por soluções, inclusive financeiras e, mudar a imagem dos doentes atingidos, deixando-os de ser "aberração a ser escondida" (p. 84). Como resultado final deste processo tem-se no início dos anos 2000 o primeiro laboratório farmacêutico, sem fins lucrativos, voltados para tratamentos das miopatias.

Voltado para o âmbito CTS podemos relacionar com o potencial das propostas centradas no conceito de Tecnologia Social (TS) que possui, dentre outros objetivos, um desenvolvimento de CT voltada para demandas sociais, políticas, econômicas e ecológicas da sociedade em que é desenvolvida. Esse conceito surge como uma contraposição à Tecnologia Convencional que, de maneira geral, está alinhada aos propósitos das grandes empresas, como segmentação do trabalho e produto, alienação, hierarquização, monopolização, uso de máquinas ambientalmente insustentáveis, dentre outros (DAGNINO, 2010). O autor, que pertence à corrente do PLACTS, destaca a Adequação Sócio-Técnica (AST) como uma das formas de operacionalização da TS, ou seja, um processo de geração de conhecimento orientado por interesses e valores compatíveis com contexto e demandas locais e, com a participação ampliada dos atores sociais. Essa perspectiva possui, dentre outras modalidades, a busca pela revitalização e/ou reprojetamento de máquinas e equipamentos, alternativas tecnológicas, incorporação do conhecimento científico-tecnológico existente e produção e 
incorporação de conhecimento novo (DAGNINO, 2010). Além disso, por ter preocupação com os empreendimentos autogestionários, possuem pressupostos voltados para substituir "a competição entre os trabalhadores pela solidariedade, e a fragmentação pelo coletivismo" (p. 275), oferecendo uma possibilidade de inclusão social e de construir alternativas aos procedimentos formais da lógica da competitividade que leva a uma insustentabilidade social, ambiental e econômica.

Com relação à educação CTS, podemos destacar a perspectiva ressaltada por Roso (2017) quando afirma que o conceito de TS tem orientado novas formas de formação dos sujeitos, estas organizadas, por exemplo, a partir de questionamentos e "exercício curricular" que envolve valores outros que não apenas os constitutivos da ciência, problematizando formas alternativas de organização social, bem como de demandas contextuais. Junto a isso, destacamos também as práticas freireanas que tem a preocupação de engajar diferentes saberes e atores sociais e construir o conhecimento de maneira coletiva no processo educativo, ou seja, àquelas que efetivamente envolvem os estudantes em todo o processo. Essas perspectivas se aproximam de um olhar para o currículo, processos e práticas educativas que estão relacionadas a uma forma de pensamento complexo. Este possibilita interagir com maior amplitude e criticidade frente a situações vivenciadas, inclusive problemas sociais de CT, que são complexos por natureza, ou seja, contribui para pensarmos o global, mas também os elementos que compõem o todo. Além disso, permite inserir problematizações referentes a desigualdade social; dimensões axiológicas, como ética e moral; produção "multidimensional de conhecimento" (MORIN, 2015) e colaboração e participação conjunta. Portanto, contribuições de extrema relevância para o desenvolvimento de práticas, de fato, participativas e democráticas.

\section{ENCAMINHAMENTOS PARA A EDUCAÇÃO EM CIÊNCIAS}

O movimento CTS teve com uma das principais reinvindicações, iniciadas em meados do século XX, a busca por uma maior participação da sociedade nos rumos do desenvolvimento científico-tecnológico. Objetivo este que repercutiu e orientou, mais tarde, propósitos educacionais CTS. No entanto, percebe-se que apesar de ser considerado teoricamente em muitas práticas educativas, há ainda uma lacuna referente a reflexões profundas sobre essa perspectiva. Visando contribuir com isso, este trabalho 
realizou um estudo teórico referente a entendimentos sobre processos democráticos relacionados a temas sociais de $\mathrm{CT}$ e de que maneira tais perspectivas se aproximam, distanciam e sinalizam encaminhamentos para práticas educativas que visam a constituição de uma cultura de participação.

Como destaque das discussões realizadas podemos considerar principalmente três dimensões associadas aos processos democráticos. A primeira, refletora de uma organização social e pensamento simplificado, está voltada para uma interação linear e hierarquizada entre os sujeitos. Nesta, a sociedade possui o papel de beneficiária e recebedora da CT, sendo apenas formada ou informada sobre ela, perspectiva educacional próxima da promovida pela educação bancária. A segunda dimensão é caracterizada principalmente por um processo dialógico. Nesta, a sociedade em geral possui papel mais ativo, já que é capaz de participar de parte do processo, opinando sempre que for necessário, pois possui conhecimentos e habilidades que enriquecem e complementam a dos cientistas, que podem ou não ser convertidos em ação. Potencial educacional promovido, de alguma maneira, pelos propósitos das articulações FreireCTS. E, a terceira está orientada para processos ampliados de participação social. Isso porque, além da relação dialogal do modelo anterior, há uma construção coletiva do processo de conhecimento, este considerando histórias individuais e coletivas, situações contextuais e identidades compartilhadas. O destaque desta dimensão está na compreensão de uma forma de organização e pensamento complexo que podem ser contempladas, por exemplo, com propostas centradas no conceito de TS e práticas freireanas preocupadas em envolver os estudantes em todo o processo educacional, o que inclui currículo, avaliação, gestão democrática, entre outros.

Ressaltamos a dificuldade em trabalhar com perspectivas, sentidos e práticas referente a processos democráticos, visto que por se tratar de um tema social, sua realidade é mais complexa do que de fato aquilo que verbalizamos sobre ela. Diante disso e entendendo essa problemática, o nosso intuito está em proporcionar exercícios que sirvam para (re)pensar, adaptar, avaliar, comparar e sinalizar possíveis direcionamentos para a educação científica, em especial no contexto CTS, visto que essa problemática se apresenta como lacuna neste campo. Enfim, discussões como as realizadas neste trabalho não têm como intuito respostas e conclusões imediatas. E sim 
são pautadas para gerarem inquietações e reflexões com o viés de repensarmos discursos e práticas visando novos encaminhamentos e reestruturações.

\section{REFERÊNCIAS}

AIKENHEAD, G.S. STS Education: A Rose by Any Other Name. En R. Cross, (Ed.), Vision for Science Education: Responding to the work of Peter J. Fensham, pp. 59-75. New York: Routledge Press, 2003.

AULER, D. Interações entre Ciência-Tecnologia-Sociedade no Contexto da Formação de Professores de Ciências. 2002. Tese (Doutorado em Educação), Centro de Educação, Universidade Federal de Santa Catarina, Florianópolis, 2002.

CALlON, M. Des différentes formes de démocratie technique. Responsabilité \& Environnement, n. 9, p. 63-73, 1998.

CALLON, M.; LASCOUMES, P.; BRTHES, Y. An essay on technical democracy. Paris: Seuil; 2009.

DAGNINO, R. P. Um dilema latino-americano: ciência e tecnologia para a sociedade ou adequação sócio-técnica com o povo? In: DAGNINO, R. (Org.). Estudos sociais da ciência e tecnologia e política de ciência e tecnologia: abordagens alternativas para uma nova América Latina. Campina Grande: EDUEPB, 2010c, p. 265-292.

DAGNINO; THOMAS; DAVYT. El Pensamento em Ciência, Tecnologia y Sociedade em Latinoamérica: uma interpretación política de sua trayectoria. In: DAGNINO; THOMAS. Ciência, Tecnologia e Sociedade: uma reflexão latino-americana. Taubaté: Cabral Editora e Livraria Universitária, 2003.

FREIRE, P. Pedagogia do oprimido. 48. ed. Rio de Janeiro: Paz e Terra, 2005.

GARCÍA, M. G.; CEREZO, J. A. L.; LÓPEZ, J. L. L. Ciencia, Tecnologia Y Sociedad: una introducción al estudio social de la Ciência y la tecnología. Madrid: Tecnos, 1996.

MORIN, E. Ciência com consciência. 16ª ed. Rio de Janeiro: Bertrand, 2014.

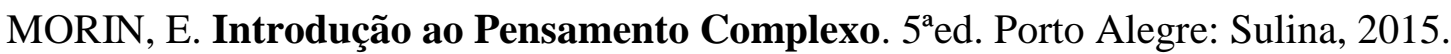

ROSA, S. E. Não Neutralidade da Ciência-Tecnologia: problematizando silenciamentos em práticas educativas relacionadas a CTS. 2014. Dissertação (Mestrado em Educação), Centro de Educação, Universidade Federal de Santa Maria, Santa Maria - RS, 2014.

ROSA, S. E.; ARAÚJO, W. Processos formativos no contexto brasileiro: uma articulação dos pressupostos de Freire e a educação CTS. In: XI Encontro Nacional de Pesquisa em Educação em Ciências, 2017, Florianópolis. Anais. Rio de Janeiro - RJ, ABRAPEC, 2017.

ROSO, C. Transformações na Educação CTS: uma proposta a partir do conceito de tecnologia social. Tese (Doutorado em Educação Científica e Tecnológica), Centro de Educação, Universidade Federal de Santa Catarina, Florianópolis, 2017. 
SAMAGAIA, R. Comunicação, divulgação e educação científicas: Uma análise em função dos modelos teóricos e pedagógicos. Tese (Doutorado em Educação Científica e Tecnológica), Centro de Educação, Universidade Federal de Santa Catarina, Florianópolis, 2016.

SANTOS, W. L. P. Educação Científica Humanística em Uma Perspectiva Freireana: Resgatando a Função do Ensino CTS. Alexandria Revista de Educação em Ciência e Tecnologia, v.1, n.1, p. 109-131, 2008.

SILVA, S.; LIMA JUNIOR, P. A democracia nas revistas de ensino de ciências no Brasil. In: XI Encontro Nacional de Pesquisa em Educação em Ciências, 2017, Florianópolis. Anais. Rio de Janeiro - RJ, ABRAPEC, 2017.

SOUSA SANTOS, B. Renovar a Teoria Crítica e Reinventar a Emancipação Social. São Paulo: Boitempo Editorial, 2007.

STRIEDER, R. B.; KAWAMURA, R. Educação CTS: parâmetros e propósitos brasileiros. Alexandria Revista de Educação em Ciência e Tecnologia, v. 10, n. 1, P. 27-56, 2017.

STRIEDER, R. B. et al. A educação CTS possui respaldo em documentos oficiais 